\title{
Modification of Malaysian dolomite using mechanochemical treatment via different media for oil palm fronds gasification
}

\begin{abstract}
Exploitation of biomass wastes gives new hopes in the exploration of clean alternative fuel source such as hydrogen energy. The application of catalysts plays a major role in the process by enhancing the production of hydrogen via reformation and tar cracking reaction. However, certain drawbacks such as catalyst cost, deactivation, and regeneration remain unsolved in this process. In this study, we focused on potential Malaysian dolomite (Perlis) as the source of catalysts for palm frond gasification. The influences of mechanochemical treatment in three different media (air, ethanol, and water) on the catalytic activity of the material were analyzed. Important changes in the properties of the dolomite along with the high catalytic performance were noted as the results of the treatment. Notable changes in the dolomite structure and porosity were observed because of the impact of the treatment. Increment in the surface area of the catalysts boosts the $\mathrm{H} 2$ production and catalytic activity of dolomite. Moreover, substantial $\mathrm{CO} 2$ reduction was also observed during reaction as a result of the absorption capacity of treated dolomite. Thus, through mechanochemical treatment, the property of Malaysian dolomite is being greatly altered, which really suits as a potential catalyst for gasification.
\end{abstract}

Keyword: Dolomite; Tar cracking; Gasification; Hydrogen; Mechanochemical treatment; Oil palm frond 